\title{
On a unique constitutive equation for steady state isotropic optimal structural superplastic deformation in all classes of materials
}

\author{
K. R. Harisankar ${ }^{1}$, S. Sripathi ${ }^{2}$, K. A. Padmanabhan ${ }^{\dagger, 1,3}$ \\ †ananthaster@gmail.com
${ }^{1}$ TCS Research, Tata Research Development and Design Centre (TRDDC), Tata Consultancy Services Ltd., 54-B, Hadapsar Industrial Estate, Pune 411013, India
${ }^{2}$ Department of Mechanical Engineering, Ramaiah Institute of Technology, Bengaluru, Karnataka, 560054, India ${ }^{3}$ Materials Science \& Engineering Programme, Department of Mechanical Engineering, College of Engineering Guindy, Anna University, Chennai, 600025, India

\begin{abstract}
Structural Superplasticity in materials has been reported in so many different classes of materials that there is a case to state that this phenomenon is (near)-ubiquitous. Yet, many authors have proposed different rate controlling processes for different superplastic materials. Such an approach goes against Newton's (Principia, Part 3) axiom that "to the same natural effects we must, so far as possible, assign the same causes". In contrast, a viewpoint also exists that steady state, isotropic, optimal structural superplastic deformation in different classes of materials can be attributed to a grain-boundary-slidingrate-controlled process that develops to a mesoscopic scale (defined to be of the order of a grain diameter or more). If this were the case, it should be possible to generate in properly normalized spaces material-independent "universal" curves (2D) and surfaces (3D) for the relationships among the different experimental variables/parameters like stress, strain rate, strain rate sensitivity index, temperature, real activation energy for the rate controlling process and viscosity. In this paper, by a careful analysis of experimental data concerning 175 states of superplastic materials of different classes it is demonstrated that such universal curves and surfaces indeed exist. The existence of such universal curves and surfaces that describe the phenomenology of steady state, isotropic, optimal structural superplastic deformation in different classes of materials in terms of unique equations reinforces the view experimentally arrived at that a unique physical mechanism of deformation is responsible for the near-ubiquitous phenomenon of steady state, isotropic, optimal structural superplasticity.
\end{abstract}

Keywords: superplastic deformation, phenomenology, steady state flow, isotropic optimal superplastic flow, optimal superplasticity, universal flow curves and surfaces, normalized variables.

\section{О едином определяющем уравнении стационарной} изотропной оптимальной структурной сверхпластической деформации во всех классах материалов

\author{
Харисанкар К. Р. ${ }^{1}$, Шрипати Ш. ${ }^{2}$, Падманабхан К. А. ${ }^{\dagger, 1,3}$ \\ ${ }^{1}$ Центр исследований и дизайна Тата, Тата Консалтанси Сервисиз Лтд., 54-В, Промышленная зона Хадапсар, \\ Пюн, 411013, Индия \\ ${ }^{2}$ Кафедра машиностроения, Технологический институт Рамая, Бангалор, Карнатака, 560054, Индия \\ ${ }^{3}$ Кафедра материаловедения и машиностроения, факультет машиностроения, Инженерный колледж Гинди, \\ Университет Анна, Ченнай, 600025, Индия
}

\begin{abstract}
Структурная сверхпластичность материалов обнаружена в столь различных классах материалов, что есть основания утверждать, что это явление является (почти) универсальным. Тем не менее, многие авторы предлагали разные модели контролирующих скорость деформации процессов для разных сверхпластичных материалов. Такой подход противоречит аксиоме Ньютона (Principia, часть 3) о том, что «одним и тем же естественным эффектам мы должны, насколько это возможно, приписывать одни и те же причины». Существует также другая точка зрения, что стационарная, изотропная, оптимальная структурная сверхпластическая деформация в различных
\end{abstract}


классах материалов может быть приписана процессу, контролируемому скоростью скольжения по границам зерен, который развивается до мезоскопического масштаба (порядка диаметра зерен или больше). Если бы это было так, то появилась бы возможность генерировать в должным образом нормированных пространствах независимые от материала «универсальные» кривые (2D) и поверхности (3D) для соотношений между различными экспериментальными переменными/параметрами, такими как напряжение, скорость деформации, коэффициент скоростной чувствительности, температура, энергия активации контролирующего скорость процесса и вязкость. В настоящей работе путем тщательного анализа экспериментальных данных по 175 состояниям сверхпластичных материалов различных классов показано, что такие универсальные кривые и поверхности действительно существуют. Существование таких универсальных кривых и поверхностей, описывающих феноменологию стационарной, изотропной, оптимальной структурной сверхпластической деформации в различных классах материалов в терминах единых уравнений, подкрепляет экспериментально полученное представление о том, что за почти универсальное явление стационарной, изотропной, оптимальной структурной сверхпластичности ответственен единый физический механизм деформации.

Ключевые слова: сверхпластическая деформация, феноменология, стационарное течение, изотропное оптимальное сверхпластическое течение, оптимальная сверхпластичность, универсальные кривые и поверхности течения, нормированные переменные.

\section{Introduction}

Superplastic forming is an advanced, near-net-shape forming process of parts and components used in aerospace, surface transport, architecture and many other industries. A classical definition of Structural Superplasticity used to be that it is a phenomenon exhibited by micron-grained polycrystalline materials at relatively low strain rates and high homologous temperatures that permits them to be stretched by several hundreds of percent in length under the action of a small tensile stress. High strain rate superplasticity results when the grain size is reduced to sub-micron or nanometer level. In such materials the temperature of superplastic deformation can also be brought down significantly. Structural superplasticity is observed in different classes of materials, viz. metals and alloys, intermetallic compounds (intermetallics), ceramics, composites, bulk metallic glasses, geological materials, ice/ice-mixtures and nanocrystalline materials. In these materials the grain size can vary from a few micrometers down to a few nanometers. Therefore, it appears reasonable to suggest that Structural Superplasticity is a near-ubiquitous phenomenon that is observed in almost all classes of materials under appropriate experimental conditions [1]. Such a view led to a search for a common rate controlling physical mechanism which would facilitate an understanding of steady state, isotropic, optimal superplastic flow in all classes of materials on a common basis. Based on unequivocal experimental evidence, most of the authors have concluded that optimal superplastic flow is dominated by grain boundary sliding (GBS) [1-9]. Diffusional flow and dislocation activity are suggested to be present to a limited extent $[1-4,10]$. There is an ongoing debate as to whether grain boundary sliding itself can be the rate controlling process [11-22] or some other physical process controls the rate of grain boundary sliding [3-4,10,23-26] during steady state, isotropic, optimal superplastic deformation. In contrast, a few analyses have focused on stress-directed diffusive control [27], internal state variables applicable for the whole field of inelasticity [28], inhomogeneity in microstructures [29] and peculiarities of deformation and damage [30] as responsible for the phenomenon of Superplasticity.
When different rate controlling mechanisms are invoked, as done by many authors, to explain structural Superplasticity in different materials one is open to a criticism that the same phenomenon is explained in different ways in different materials. A powerful argument in favour of grain boundary sliding rate controlled flow in materials that exhibit steady state, isotropic, optimal Structural Superplasticity [13-14,19-21] is that it is able to explain this phenomenon in materials of different classes and grain sizes that could range from a few nanometers to a few micrometers on a common basis using a clearly defined physical model for grain boundary sliding. Ever since Newton (Principia, Part 3) the axiom/belief that "to the same natural effects we must, so far as possible, assign the same causes" has dominated science.

If the assumption, based on experimental results, of a unique rate controlling physical process underlying steady state isotropic, optimal superplastic deformation in all classes of materials is correct, it stands to reason that the interrelationships among the experimental variables/parameters in the phenomenology of superplastic deformation in properly normalized spaces - in which the different experimental variables/quantifiable entities are rendered dimensionless and made to possess comparable magnitudes, as required by Dimensional Analysis - should be describable in terms of universal curves/surfaces, which are independent of the material and its class. Evidently, this will not be the case if the rate controlling deformation process changes from one material to the next. In the past, using limited experimental data, this concept of the "universal nature of superplastic behavior" was probed rather tentatively [13,31-34].

It is well-known that the rheological response during optimal superplastic deformation is viscoplastic (nonNewtonian viscous), i.e., the apparent viscosity decreases with increasing strain rate in the optimal strain rate range (assumed to be present from the lowest strain rate till the point of inflection in the sigmoidal log stress - log strain rate curve) $[2,4,35$ - 36]. In addition, if a common rate-controlling mechanism for optimal superplastic flow is present in all superplastic materials of all classes, the real activation energy for the rate controlling process compensated for the melting temperature on the absolute scale of the concerned material should be a constant value. This is because the real 
activation energy for a rate controlling process is directly related to the strength of the atomic bonds and hence the shear strength/modulus of a material, which for a unique mechanism of deformation should be constant for all classes of superplastic materials if it is compensated for the melting temperature of the material on the absolute scale (a linear approximation).

Materials scientists searched for the physical mechanisms of structural superplastic flow in different classes of materials without first verifying if a phenomenological description of steady state, isotropic, optimal Structural Superplasticity can be reduced to a unique form in terms of normalized experimental/phenomenological variables/parameters. From the viewpoint of mechanics this is a prerequisite for initiating a search for a common underlying physical mechanism. Here we examine if superplastic deformation in different classes of materials, viz. metals and alloys, intermetallics, ceramics, composites, bulk metallic glasses, geological materials, ice/ice-mixtures and nanostructured materials, can be represented by a unique curve (in $2 \mathrm{D}$ plots) or a unique surface (in 3D plots). Universal curves and surfaces will be obtained by normalizing the determinable quantities of stress $(\sigma)$, strain rate $(\dot{\varepsilon})$, strain rate sensitivity index $(m)$, temperature of deformation on the absolute scale $(T)$, real activation energy needed for the rate controlling process $(Q)$ and apparent viscosity $\left(\eta_{\text {app }}\right)$ with respect to carefully chosen reference values to render them dimensionless (as required by Dimensional Analysis). By analyzing a mass of experimental results pertaining to different classes of superplastic materials, a case is made that a (near) material-independent universal relationship in a normalized, dimensionless $\sigma-\dot{\varepsilon}-m-\eta-T-Q$ (hyper)-space exists for steady state, isotropic, optimal superplastic deformation. While doing this, there will be strict adherence to the phenomenological equations commonly used in Superplasticity literature.

\section{Analytical Procedure}

Following the standard practice in Superplasticity literature, a constant grain size, isothermal sigmoidal log (stress, $\sigma)-\log ($ strain rate, $\dot{\varepsilon})$ curve describing superplastic flow and a schematic indicating the variation of the strain rate sensitivity index, $m$, with strain rate, $\dot{\varepsilon}$, both taken from [2], are presented in Supplementary Material as Figs. S1 and S2. Initially $m$ increases with increasing $\dot{\varepsilon}$ and after reaching a peak value, it decreases with a further increase in strain rate. The value of $\dot{\varepsilon}$ at maximum $m$ value is defined as the optimal strain rate $\left(\dot{\varepsilon}_{\text {opt }}\right)$ for superplastic flow because at this strain rate in numerous experiments maximum elongation to fracture is observed in isothermal tensile tests in materials of constant grain size. The maximum value of $m$ is denoted as $m_{\max }$ and the corresponding stress on the sigmoidal curve, Fig. S1, is defined as the optimal stress $\left(\sigma_{\text {opt }}\right)$.

The strain rate sensitivity index $(m)$ is dependent on grain size, temperature and stress. The value of $m$ increases with decreasing grain size and/or increasing temperature, but goes through a maximum with increasing stress/strain rate. In micro-duplex alloys, the maximum value of $m$ is often observed at the upper limiting temperature of the two-phase field, but if the alloy is prone to grain coarsening, the temperature of maximum $m$ value could be lower. The temperature dependence of $m$ is more in region II of Fig. S2 and the absolute value of $m$ can be increased by either increasing the temperature of deformation and/or decreasing the grain size. The region in the vicinity of $m_{\max }$ of region II is known as optimal superplastic deformation because beyond that strain rate dislocation processes of low $m$ value $(<0.3)$ commence to operate, $m$ decreases with a further increase in strain rate and Superplasticity is gradually lost. Based on a few semi-empirical analyses, it has been concluded that the elongation at failure in a tensile test of a superplastic alloy is approximately proportional to $m^{2}$. As the elongation at fracture becomes quite significant when $m \geq 0.3$, by convention it has been agreed that for the presence of industrially relevant levels of superplastic deformation, $m$ should be greater than or equal to 0.3 . It is evident, therefore, that the best superplastic effects in an alloy of constant grain size and a given temperature of deformation are seen when $m=m_{\text {max }}, \dot{\varepsilon}=\dot{\varepsilon}_{\text {opt }}, \sigma=\sigma_{\text {opt }}[2]$.

For a given sigmoidal curve at constant grain size and temperature, $\sigma_{\text {opt }}, \dot{\varepsilon}_{\text {opt }}$ and $m_{\text {max }}$ are taken as the normalization bases for stress, strain rate and strain rate sensitivity index respectively. Further, the test temperature on the absolute scale is normalized with respect to the melting point of the material on the absolute scale and such a normalization gives rise to, what is known as, the homologous temperature $\left(T_{\text {hom }}=T / T_{\mathrm{m}}\right)$. The melting points of the alloys selected for this study are taken from the open literature.

The real activation energy for the rate controlling mechanism in the case of optimal structural superplasticity is calculated using the method outlined in [37]. For the case of constant microstructure, the following equations are valid.

$$
\begin{aligned}
& \dot{\varepsilon}=A_{3} \sigma^{*_{n}} \exp (-Q / k T) ; \text { if it is taken that } v=\left(k T / h s^{-1}\right), \\
& \dot{\varepsilon}=\left(\frac{A_{4}}{T}\right) \sigma^{*_{n}} \exp (-Q / k T) ; \text { if it is taken that } v=\left(10^{13} s^{-1}\right),
\end{aligned}
$$

where $v$ is thermal vibration frequency. The constants $A_{3}$ and $A_{4}$ are independent of $\sigma$ and $T$ (but dependent on grain size), but are inter-related; i. e., $A_{4}=\left(10^{13} A_{3} \cdot h / k\right)$. (The magnitude of $A_{3}$ is determined empirically at the level of phenomenology, but it can be computed $a b$ initio in the physical model) $[13-14,19-21] . Q$ is the real activation energy for the rate controlling process. Here $h$ is the Planck constant, $k$ is the Boltzmann constant and $\sigma^{*}=(\sigma /(e \sigma))$ is the dimensionless stress, with $e$ the base of the natural logarithms. $\sigma_{c}$ is the stress at which $m=1$ in the dimensionless strain rate-stress space $\left(\dot{\varepsilon}^{*}-\sigma^{\star}\right.$ space) $[12,37]$. (It is readily seen that in these calculations the strain rate is normalized with respect to unit strain rate $\left(1 \mathrm{~s}^{-1}\right)$ to make it dimensionless, i. e. $\dot{\varepsilon}^{\star}=(\dot{\varepsilon} / 1)$. In view of this identity, $\dot{\varepsilon}$ is used here onward without a star symbol even though it is dimensionless. Moreover, it is clear that the condition $0<\sigma^{\star}<1$ is satisfied and as a result a problem of convergence that could arise if any function of stress were expanded in a power series is avoided.

The need to make stress dimensionless $\left(\sigma^{\star}\right)$, and the physical meaning of the symbols $\sigma_{c}, p_{\mathrm{o}}$ are explained in detail elsewhere [11-12,37]. For completeness, a short account of the same is given in the Supplementary Material as Appendixes S. A and S. B. 
During steady-state, isotropic superplastic deformation in the optimal range, the stress exponent, $n$ (the inverse of the strain rate sensitivity index, $m$ ), is strongly dependent on stress, grain size and temperature. It has been shown that the solution for this case is $[12,37]$

$$
n=\left(\frac{\partial \ln \dot{\varepsilon}}{\partial \ln \sigma}\right)=\left(1+p_{0}\right)-\left(\frac{p_{0}}{\sigma_{c}}\right) \sigma=B-C \sigma,
$$

where $p_{0}=\left(n_{0}-1\right)$, with no the value of $n$ as the stress/strain rate tends to zero. (The notation $p_{0}$ is introduced in place of $\left(n_{0}-1\right)$ to simplify the equation.) Thus, one finds that in the optimal range of superplastic deformation $n$ decreases linearly with increasing stress. $B$ and $C$ are grain size- and temperature-dependent constants. The above equations have to satisfy two constraints [37]: (i) $p_{0}$ should decrease with increasing temperature and always have a positive value greater than or equal to 1 (based on the experimental observations that $n$ decreases with increasing temperature and always has a value greater than or equal to 1) and $\sigma$ (the stress at which $n=m=1$ in the dimensionless $\dot{\varepsilon}-\sigma^{\star}$ space) also should decrease with increasing temperature and always have a value greater than $\sigma_{\text {opt }}$ at every temperature. (By convention, $\sigma$ is taken as positive for a tensile test). (ii) Under isothermal and constant grain size conditions $p_{0}=C \sigma_{\mathrm{c}}$ (see Eq. (2)). That is, $\left(C_{i} / C_{(i-1)}\right)$ should always be equal to $\left(p_{0 i} / p_{0(i-1)}\right) \times\left(\sigma_{c(i-1)} / \sigma_{c i}\right)$, where the subscripts $(i)$ and $(i-1)$ correspond to two different temperatures $T_{\mathrm{i}}$ and $T_{i-1} \cdot p_{0}$ and $\sigma_{c}$ values are calculated individually for the two different isothermal tests, using a material of constant grain size and Eq. (2). Further details are given in Supplementary Material - see Appendixes S. A and S. B.

It has further been shown that the real activation energy for the rate controlling process in superplastic flow is calculated from the equation [37],

$$
\begin{aligned}
& \ln \dot{\varepsilon}= \ln A_{3}+2 p_{0}+ \\
&+\left(1+p_{0}\right) \ln \left(\sigma / e \sigma_{c}\right)-p_{0}\left(\sigma / \sigma_{c}\right)-Q / k T \\
& \ln \dot{\varepsilon}+\ln T=\ln A_{4}+2 p_{0}+ \\
&+\left(1+p_{0}\right) \ln \left(\sigma / e \sigma_{c}\right)-p_{0}\left(\sigma / \sigma_{c}\right)-Q / k T
\end{aligned}
$$

Evidently, the above equations correspond to the cases $v=(k T / h)$ or $v=10^{13} \mathrm{~s}^{-1}$ respectively.

When $v=(k T / h)$, a plot of $\ln \dot{\varepsilon}$ vs $(1 / T)$ at a constant value of $\left[2 p_{0}+\left(1+p_{0}\right) \ln \left(\sigma / e \sigma_{c}\right)-\left(p_{0} \sigma / \sigma_{c}\right)\right]$ is prepared, the slope of which is equal to $(-Q / k)$. The value of $Q$ thus obtained should be and has been verified to be independent of the magnitude of $\left[2 p_{0}+\left(1+p_{0}\right) \ln \left(\sigma / e \sigma_{c}\right)-\left(p_{0} \sigma / \sigma_{c}\right)\right]$, which is kept constant. Similarly, when $v=10^{13} \mathrm{~s}^{-1}$, the slope of a plot of $(\ln \dot{\varepsilon}+\ln T)$ vs $(1 / T)$ at a constant value of $\left[2 p_{0}+\left(1+p_{0}\right) \ln \left(\sigma / e \sigma_{c}\right)-\left(p_{0} \sigma / \sigma_{c}\right)\right]$ is equal to $(-Q / k)$. The value of $Q$ thus obtained is, again, independent of the magnitude of $\left[2 p_{0}+\left(1+p_{0}\right) \ln \left(\sigma / e \sigma_{c}\right)-\right.$ $\left.-\left(p_{0} \sigma / \sigma_{c}\right)\right]$ that is kept constant [37]. Then, the real activation energy for the rate controlling process during superplastic flow, $Q$, is normalized with respect to $\left(k T_{\mathrm{m}}\right)$ (or $\left(R T_{\mathrm{m}}\right)$ (the latter, if the value of $Q$ is reported per mole) to render it dimensionless and material-independent. The assumption made while arriving at this last step is that the real activation energy for a given deformation process in a material is a linear function of its melting temperature on the absolute scale.

As mentioned earlier, superplastic deformation is (nonNewtonian) viscoplastic $[1-2,36]$. When the von Mises yield criterion is used (it is straightforward to use any other yield criterion of choice; only the value of the numerical constant $(=3)$ will change $[17,18])$, by definition the apparent viscosity is equal to $(\sigma /(3 \dot{\varepsilon}))$. It is then normalized with respect to the absolute viscosity, $\eta_{\text {abs }}$, (Newtonian viscosity), which is obtained as $\left(\sigma_{c} /\left(3 \dot{\varepsilon}_{c}\right)\right)$, where $\dot{\varepsilon}_{c}$ is the strain rate corresponding to $\sigma_{c}$ (which is calculated from Eqs. (2), (3a), (3b) for different isothermal conditions), because $\sigma_{c}$, by definition, is the stress at which $m=1$ in the dimensionless $\log \dot{\varepsilon}-\log \sigma^{\star}$ space and $\dot{\varepsilon}$ is the corresponding strain rate (Newtonian viscous flow). The algorithm used for these computations is given in Fig. 1 and the same algorithm was used to obtain the required numerical values for the different classes of superplastic materials for which adequate experimental data could be found. The details of calculation are given in the Supplementary Material as Appendix S. B.

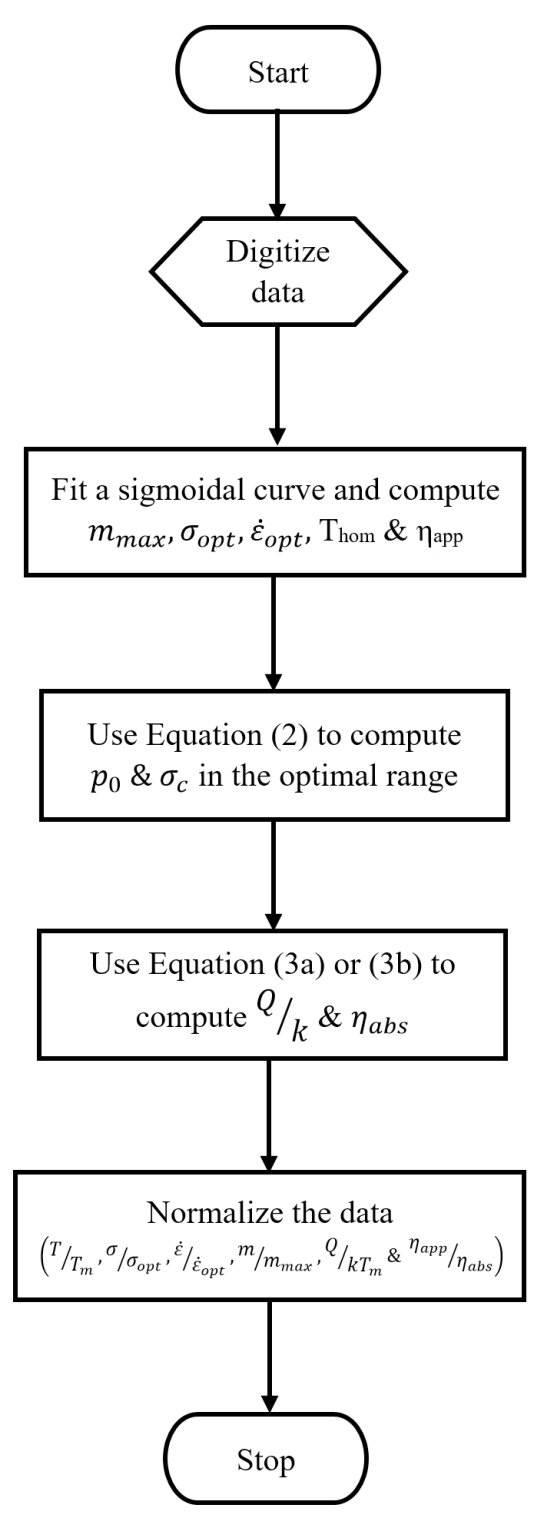

Fig. 1. Flow chart describing the algorithm used for the present work. 


\section{Results}

Table S1, given in the Supplementary Material, displays the details of the normalization bases, the computed constants and the normalized value $\left(Q / k T_{\mathrm{m}}\right)$, in case of the different classes of superplastic materials examined in this study using the algorithm presented in Fig. 1. In all, experimental data pertaining to 175 material conditions were analyzed. Eq. (2) is solved by the method of least squares using the particle swam optimization solver available in the pyswarm package [38-39]. Relationships were plotted using the computed values as curves in $2 \mathrm{D}$ and surfaces in $3 \mathrm{D}$ in the relevant normalized spaces. The $2 \mathrm{D}$ plots are $\left(Q / k T_{\mathrm{m}}\right)$ values for superplastic materials of all classes, $\log$ (normalized stress) vs. $\log$ (normalized strain rate); normalized $m$ vs. $\log$ (normalized strain rate); and $\log$ (normalized viscosity) vs. $\log$ (normalized strain rate). The $3 \mathrm{D}$ surfaces are $\log$ (normalized stress) vs. $\log$ (normalized strain rate) vs. $T_{\text {hom }}$; normalized $m$ vs. $\log$ (normalized strain rate) vs. $T_{\text {hom; }}$; and $\log$ (normalized viscosity) vs. $\log$ (normalized strain rate) vs. $T_{\text {hom }}$

The 2D plot of $\left(Q / k T_{\mathrm{m}}\right)$ for different materials for $v=(k T / h)$ is given in Fig. 2 and the mean value of $\left(Q / k T_{m}\right)$ for all classes of superplastic materials is estimated as 15.34 with a standard deviation of \pm 2.16 , i. e. the steady state, isotropic, optimal superplastic deformation in materials of all classes has a real activation energy for the rate controlling process which obeys the relation

$$
\left(Q / k T_{m}\right)=15.34 \pm 2.16
$$

The 2D plots of $\log$ (normalized stress) vs. $\log$ (normalized strain rate), normalized $m$ vs. $\log$ (normalized strain rate) and $\log$ (normalized viscosity) vs. $\log$ (normalized strain rate) were also constructed. Following usual practice [2-4], the plots are divided into 3 domains based on the $m$ value/strain rate range and are given in Fig. $3 \mathrm{a}-\mathrm{i}$. A quadratic curve is fitted to the $2 \mathrm{D}$ plots in each domain and the $R^{2}$ values (see Appendix S.C, included as Supplementary Material, for details) are calculated to estimate the deviation from the mean curve.

The meaning of the symbols used in these plots, along with the materials and the conditions of testing is given as Fig. S3 in the Supplementary Material.
A quadratic surface is fitted to the normalized data ranging from the lowest strain rate to the highest strain rate employed in the tests, i.e. in addition to the optimal region of superplastic flow, the regions of non-optimal superplastic deformation at either end of the optimal strain rate range are also taken into account in these plots. The universal 3D surfaces are presented in Fig. $4 \mathrm{a}-\mathrm{c}$.

\section{Discussion}

From the 2D plot (Fig. 2) of ( $\left.Q / k T_{\mathrm{m}}\right)$ for different materials, it is observed that the value of $\left(Q / k T_{m}\right)$ for superplastic materials of all classes taken together is nearly constant with a mean value of 15.34 and the actual values are evenly distributed on either side of the mean line, regardless of the material class. The relatively small deviation from the mean line is most likely due to experimental scatter. It is clear that the "common nature of the underlying rate controlling mechanism" (whatever it is) is established in this normalized space, particularly when one notes that the $\left(Q / k T_{m}\right)$ value is obtained from a transcendental (exponential) equation, which, by its nature, can lead to significant scatter in the computed values, see Eqs. (1) and (3).

The mean curve equations and the $R^{2}$ values for the normalized plot of $\log$ (stress) vs. $\log$ (strain rate) (Fig. $3 \mathrm{a}-\mathrm{c}$ ) are given as Eq. (5). Similarly, for the normalized $m$-normalized $\log$ (strain rate) plots (Fig. $3 \mathrm{~d}-\mathrm{f}$ ) the mean curve equations are available as Eq. (6). It is clearly seen that the correlation is the best in the optimal range of $\log$ (stress) $-\log$ (strain rate) and $m-\log$ (strain rate) plots where the condition $0.3<m \leq m_{\max }$ is obeyed. The fit is "least good" in the domain $0<m \leq 0.3$ where the low $m$ value is traced at least in some physical models to the presence of a threshold stress that should be overcome for the onset of dominant grain boundary sliding (see, for example, [2-4,13-21,40-41]). Taking the particular model in Padmanabhan et al. [see, for example, 13,14,20], as an example, it can be pointed out that the threshold stress necessary for the onset of large scale (mesoscopic) grain boundary sliding, say, in an intermetallic will be significantly more than that required for a pseudosingle phase superplastic alloy. This is the origin of the greater scatter in this lower non-optimal superplastic region. The fit is better, although still "less good" than in the optimal region, at

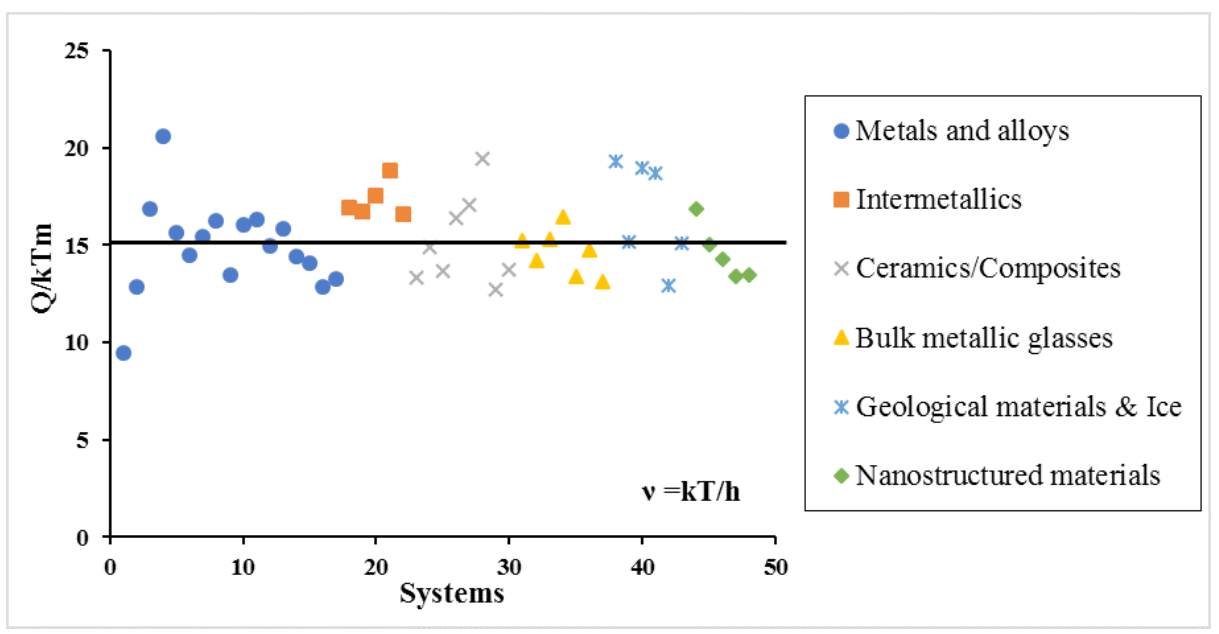

Fig. 2. (Color online) $\left(Q / k T_{\mathrm{m}}\right)$ vs. Superplastic materials. 


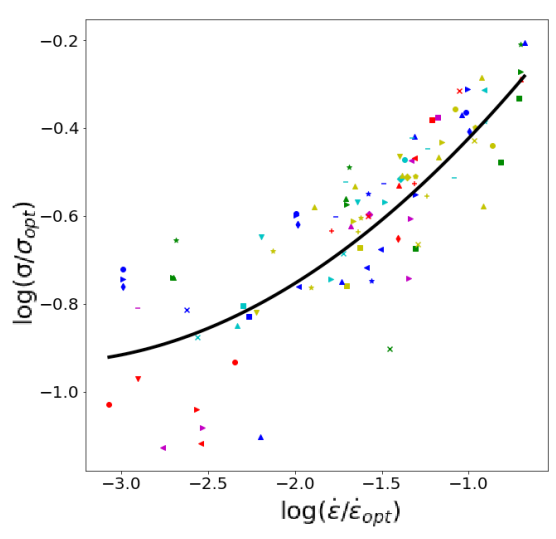

a

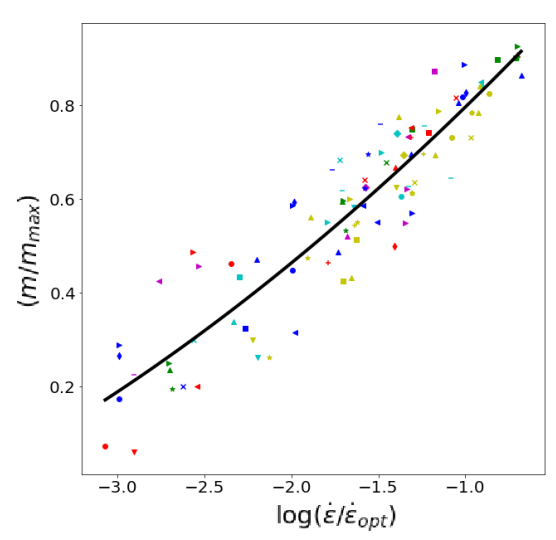

d

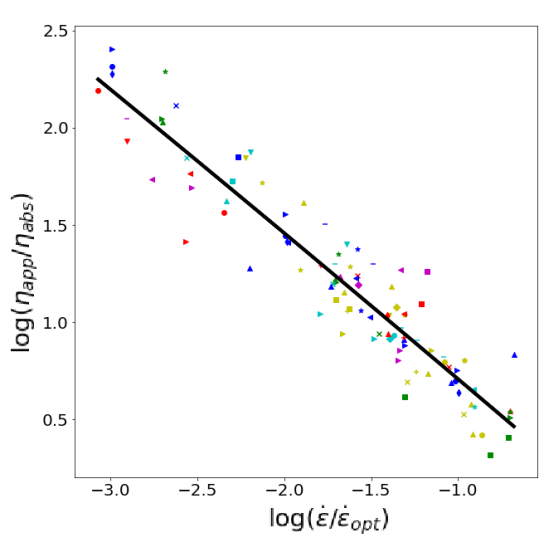

$\mathrm{g}$

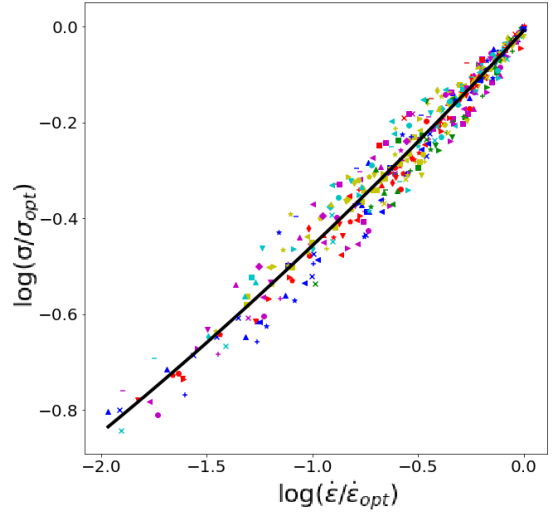

b

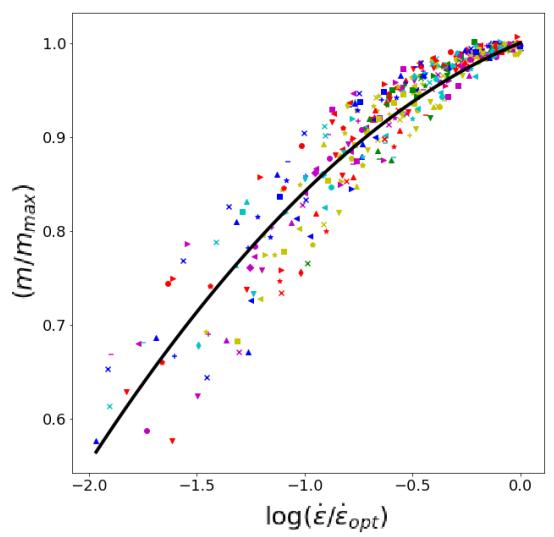

e

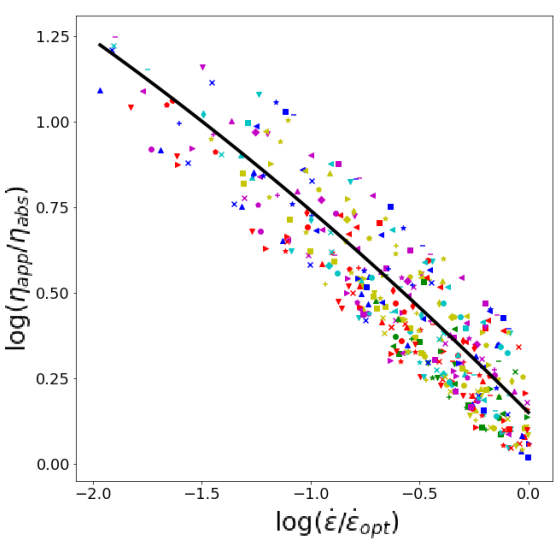

$\mathrm{h}$

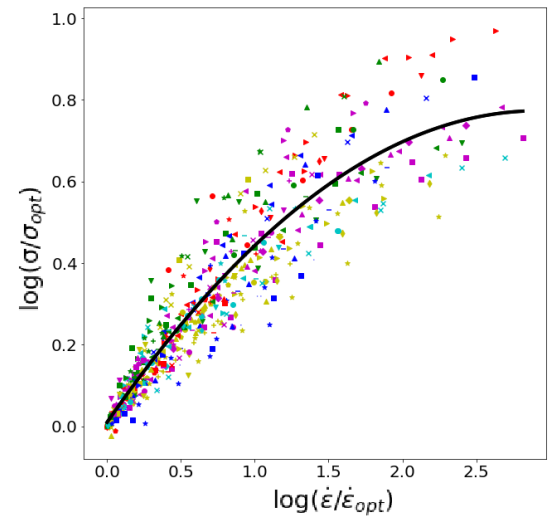

C
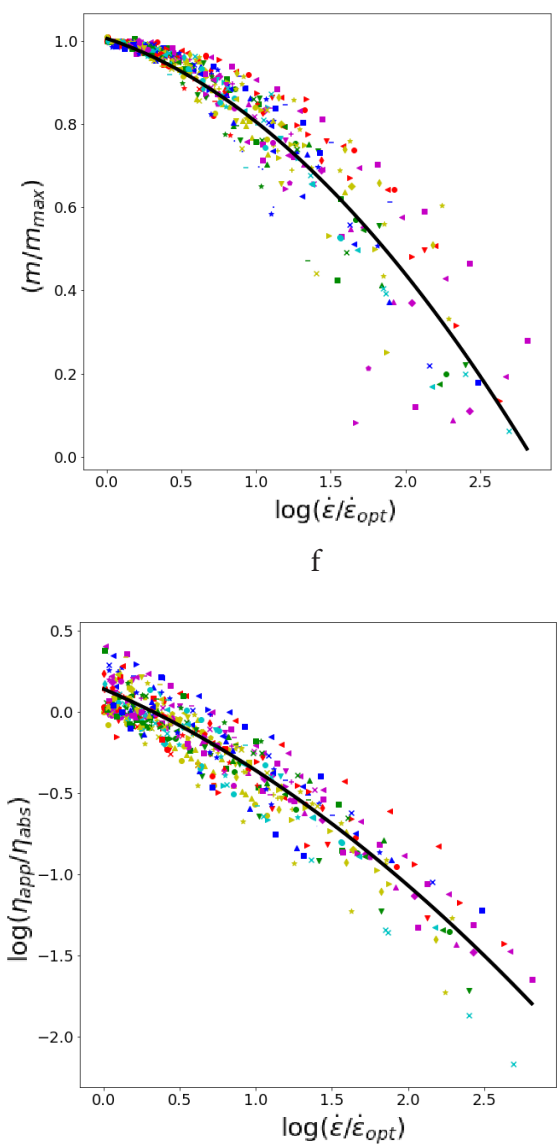

i

Fig. 3. (Color online) $2 \mathrm{D}$ plots normalized stress-normalized strain rate curves (a-c), normalized $m$-normalized strain rate curves (d-f), normalized viscosity-normalized strain rate curves (g-i). $0<m<0.3$ (a), $0.3<m<m_{\max }$ (b), $\dot{\varepsilon}>\dot{\varepsilon}_{\text {opt }}$; where $m<m_{\max }$ (c), $0<m<0.3$ (d), $0.3<m<m_{\max }(\mathrm{e}), \dot{\varepsilon}>\dot{\varepsilon}_{\text {opt }}$; where $m<m_{\max }$ (f), $0<m<0.3(\mathrm{~g}), 0.3<m<m_{\max }$ (h), $\dot{\varepsilon}>\dot{\varepsilon}_{\text {opt }}$; where $m<m_{\text {max }}$ (i).

the upper end of strain rate (beyond $\dot{\varepsilon}_{\text {opt }}$ ) where in most of the models dislocation processes are considered to be responsible for the loss of Superplasticity. In this range the response of different classes of materials is likely to be less different than in the lower end of strain rates of Superplasticity loss arising from a widely varying magnitude of the threshold stress for the onset of dominant grain boundary sliding. Nevertheless, dislocation flow characteristics are significantly affected by the crystal structure of materials, different phases present and their composition, which are different for different superplastic materials. Hence the poorer fit in this region compared with that present in the optimal strain rate range in which mesoscopic grain boundary sliding controls the rate of flow.

$$
\begin{aligned}
& \log \left(\frac{\sigma}{\sigma_{\text {opt }}}\right)=0.0837 \cdot\left[\log \left(\frac{\dot{\varepsilon}}{\dot{\varepsilon}_{\text {opt }}}\right)\right]^{2}+0.5814 \cdot \log \left(\frac{\dot{\varepsilon}}{\dot{\varepsilon}_{\text {opt }}}\right)+0.0956, \\
& R^{2} \text { value }=0.63 ; 0<m<0.3, \\
& \log \left(\frac{\sigma}{\sigma_{\text {opt }}}\right)=0.02924 \cdot\left[\log \left(\frac{\dot{\varepsilon}}{\dot{\varepsilon}_{\text {opt }}}\right)\right]^{2}+0.4781 \cdot \log \left(\frac{\dot{\varepsilon}}{\dot{\varepsilon}_{\text {opt }}}\right)-0.0088, \\
& R^{2} \text { value }=0.96 ; 0.3<m<m_{\max },
\end{aligned}
$$




$$
\begin{array}{r}
\log \left(\frac{\sigma}{\sigma_{\text {opt }}}\right)=-0.0893 \cdot\left[\log \left(\frac{\dot{\varepsilon}}{\dot{\varepsilon}_{\text {opt }}}\right)\right]^{2}+0.5225 \cdot \log \left(\frac{\dot{\varepsilon}}{\dot{\varepsilon}_{\text {opt }}}\right)+0.01, \\
R^{2} \text { value }=0.84 ; \dot{\varepsilon}>\dot{\varepsilon}_{\text {opt }} ; \text { where } m<m_{\max }, \\
\frac{m}{m_{\max }}=0.02884 \cdot\left[\log \left(\frac{\dot{\varepsilon}}{\dot{\varepsilon}_{\text {opt }}}\right)\right]^{2}+0.4195 \cdot \log \left(\frac{\dot{\varepsilon}}{\dot{\varepsilon}_{\text {opt }}}\right)+1.187, \\
R^{2} \text { value }=0.70 ; 0<m<0.3, \\
\frac{m}{m_{\max }}=-0.06511 \cdot\left[\log \left(\frac{\dot{\varepsilon}}{\dot{\varepsilon}_{\text {opt }}}\right)\right]^{2}+0.09823 \cdot \log \left(\frac{\dot{\varepsilon}}{\dot{\varepsilon}_{\text {opt }}}\right)+1.0082, \\
\frac{m}{m_{\max }}=-0.092 \cdot\left[\log \left(\frac{\dot{\varepsilon}}{\dot{\varepsilon}_{\text {opt }}}\right)\right]^{2}-0.1029 \cdot \log \left(\frac{\dot{\varepsilon}}{\dot{\varepsilon}_{\text {opt }}}\right)+1.01,
\end{array}
$$

The mean curve equations and the $R^{2}$ values for the normalized plot of viscosity-strain rate relationship (Fig. $3 g-i$ ) are given in Eq. (7). It can be observed that in all the 3 domains, as defined above, the distribution of points is nearly the same with respect to the mean curve. $R^{2}$ values for all the 3 domains are also almost equal. Evidently, the normalized viscosity of the materials is (almost) independent of the rate controlling mechanism as well as the material and its class. This is understandable because viscosity is a material property, while the other variables considered like stress, strain rate and $m$ value are strongly related to the deformation mechanisms present.

$$
\begin{array}{r}
\log \left(\frac{\eta}{\eta_{\text {abs }}}\right)=-0.0058 \cdot\left[\log \left(\frac{\dot{\varepsilon}}{\dot{\varepsilon}_{\text {opt }}}\right)\right]^{2}-0.768 \cdot \log \left(\frac{\dot{\varepsilon}}{\dot{\varepsilon}_{\text {opt }}}\right)-0.054, \\
R^{2} \text { value }=0.84 ; 0<m<0.3,
\end{array}
$$

$$
\begin{array}{r}
\log \left(\frac{\eta}{\eta_{\text {abs }}}\right)=-0.0460 \cdot\left[\log \left(\frac{\dot{\varepsilon}}{\dot{\varepsilon}_{\text {opt }}}\right)\right]^{2}-0.63714 \cdot \log \left(\frac{\dot{\varepsilon}}{\dot{\varepsilon}_{\text {opt }}}\right)+0.14 \\
R^{2} \text { value }=0.82 ; 0.3<m<m_{\max }
\end{array}
$$

$$
\log \left(\frac{\eta}{\eta_{\text {abs }}}\right)=-0.1027 \cdot\left[\log \left(\frac{\dot{\varepsilon}}{\dot{\varepsilon}_{\text {opt }}}\right)\right]^{2}-0.3982 \cdot \log \left(\frac{\dot{\varepsilon}}{\dot{\varepsilon}_{\text {opt }}}\right)+0.123
$$

The quadratic equations for the 3D surfaces (Fig. $4 \mathrm{a}-\mathrm{c}$ ) are given below, along with the corresponding $R^{2}$ values. Very good correlation is found for the entire strain rate range for all the 3 plots and the highest correlation between the experimental results and the predictions is found for viscosity for reasons already stated.

$$
\begin{gathered}
\log \left(\frac{\sigma}{\sigma_{\text {opt }}}\right)=0.00967 \cdot\left[\log \left(\frac{\dot{\varepsilon}}{\dot{\varepsilon}_{\text {opt }}}\right)\right]^{2}-0.1213\left(T_{\text {hom }}\right)^{2}- \\
-0.0472 \cdot \log \left(\frac{\dot{\varepsilon}}{\dot{\varepsilon}_{\text {opt }}}\right) \cdot T_{\text {hom }}+0.4344 \cdot \log \left(\frac{\dot{\varepsilon}}{\dot{\varepsilon}_{\text {opt }}}\right)+ \\
+0.141 \cdot T_{\text {hom }}-0.0591 ; R^{2} \text { value }=0.92
\end{gathered}
$$

$$
\begin{aligned}
& \frac{m}{m_{\max }}=-0.1215 \cdot\left[\log \left(\frac{\dot{\varepsilon}}{\dot{\varepsilon}_{\text {opt }}}\right)\right]^{2}-0.01274\left(T_{\text {hom }}\right)^{2}+ \\
& +0.042 \cdot \log \left(\frac{\dot{\varepsilon}}{\dot{\varepsilon}_{\text {opt }}}\right) \cdot T_{\text {hom }}-0.042 \cdot \log \left(\frac{\dot{\varepsilon}}{\dot{\varepsilon}_{\text {opt }}}\right)+ \\
& +0.0338 \cdot T_{\text {hom }}+0.9505 ; R^{2} \text { value }=0.88 \\
& \log \left(\frac{\eta}{\eta_{\text {abs }}}\right)=0.0142 \cdot\left[\log \left(\frac{\dot{\varepsilon}}{\dot{\varepsilon}_{\text {opt }}}\right)\right]^{2}+0.0116\left(T_{\text {hom }}\right)^{2}+ \\
& \quad+0.0139 \cdot \log \left(\frac{\dot{\varepsilon}}{\dot{\varepsilon}_{\text {opt }}}\right) \cdot T_{\text {hom }}-0.6078 \cdot \log \left(\frac{\dot{\varepsilon}}{\dot{\varepsilon}_{\text {opt }}}\right)+ \\
& \quad+0.039 \cdot T_{\text {hom }}+0.1054 ; R^{2} \text { value }=0.94 .
\end{aligned}
$$

It is worthy of noting that the $R^{2}$ values are greater (and hence the accuracy of fit superior) for the $3 \mathrm{D}$ plots than for the $2 \mathrm{D}$ plots. This is because in the $2 \mathrm{D}$ plots, the normalized $\log$ (stress) vs. $\log$ (strain rate), normalized $m$ vs. $\log$ (strain rate) and the normalized $\log$ (viscosity) vs. $\log$ (strain rate) relationships are plotted ignoring the fact that all these values do not correspond to the same homologous temperature. In contrast, in the $3 \mathrm{D}$ plots the variation of these relationships with respect to the homologous temperature is also taken into account. When this is done, even in the non-optimal strain rate ranges (very low strain rates where $m<0.3$ as well as when $\dot{\varepsilon}>\dot{\varepsilon}_{\text {opt }}$ ) the threshold stresses and the stresses needed to drive the dislocation processes respectively for the different materials get normalized with respect to the melting temperature of the material concerned and the "universal surface" thus obtained covers very accurately the entire strain rate range employed in the experiments involving the superplastic materials of all classes. Thus, there is a strong case to suggest that Eqs. (4) - (6), (8) - (10) describe uniquely superplastic deformation in materials of all classes examined in this paper with a high degree of accuracy. Such a conclusion is equivalent to suggesting that a unique physical mechanism of deformation is present in the optimal region of steady state isotropic superplastic flow regardless of the material or its class, where the fit is the best between the experimental data and the predicted sigmoidal curve that describes constant grain size, isothermal superplastic flow $[1-2,4,21]$.

\section{Consequences}

The above analysis leads to the following important conclusions.

1. The real activation energy for the rate controlling process in the region of steady state, isotropic, optimal superplastic flow in all classes of materials divided by $\left(R T_{\mathrm{m}}\right)$, where $R$ is the gas constant and $T_{\mathrm{m}}$ is the melting point of the material concerned, is of a constant value, given by Eq. (4). As the melting temperature compensated real activation energy for materials of all classes is the same, a case could be made out that the physical mechanism responsible for controlling the rate of flow in the steady state, isotropic, optimal region of superplastic deformation is the same for materials of all classes. 

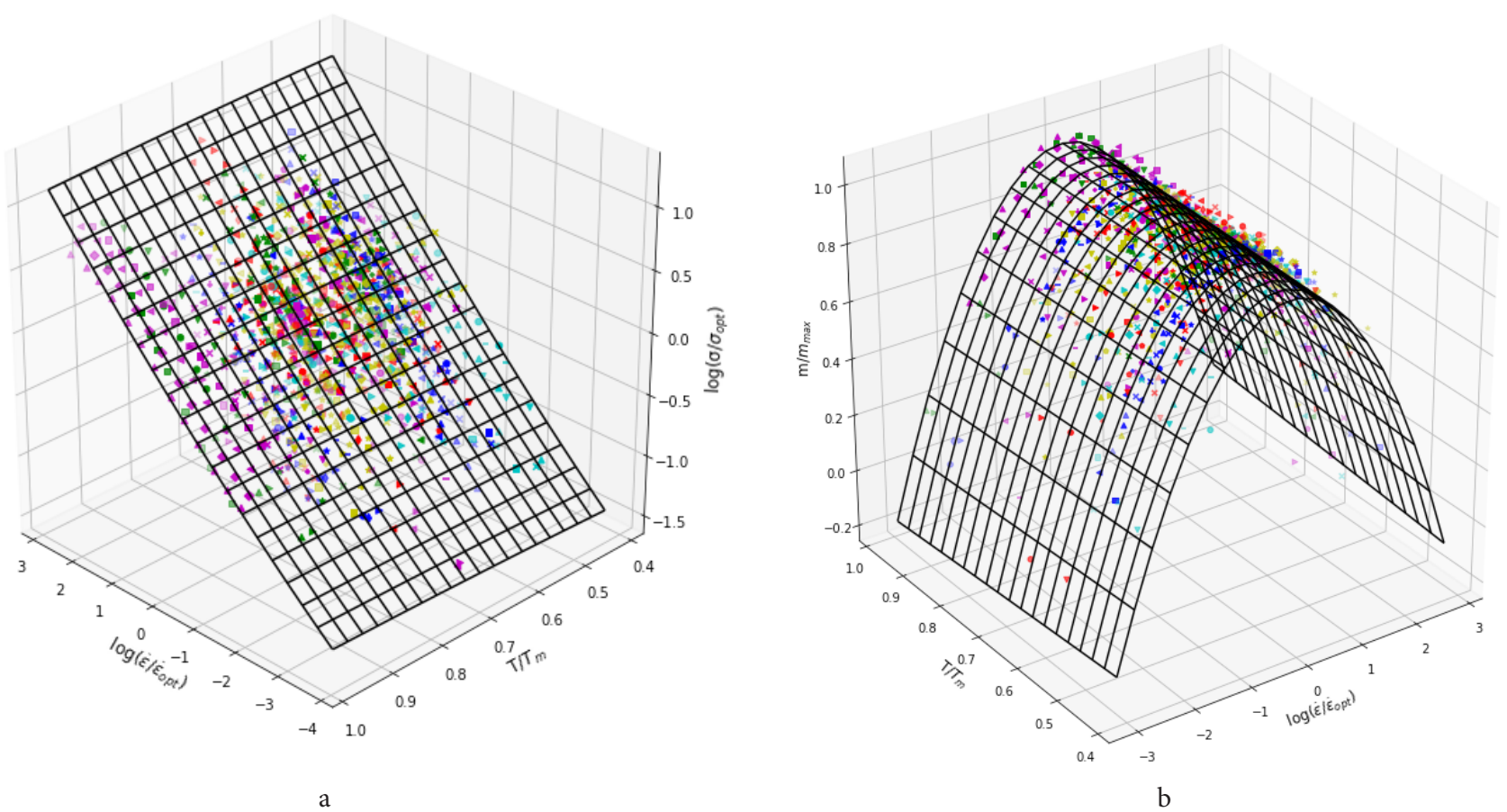

a

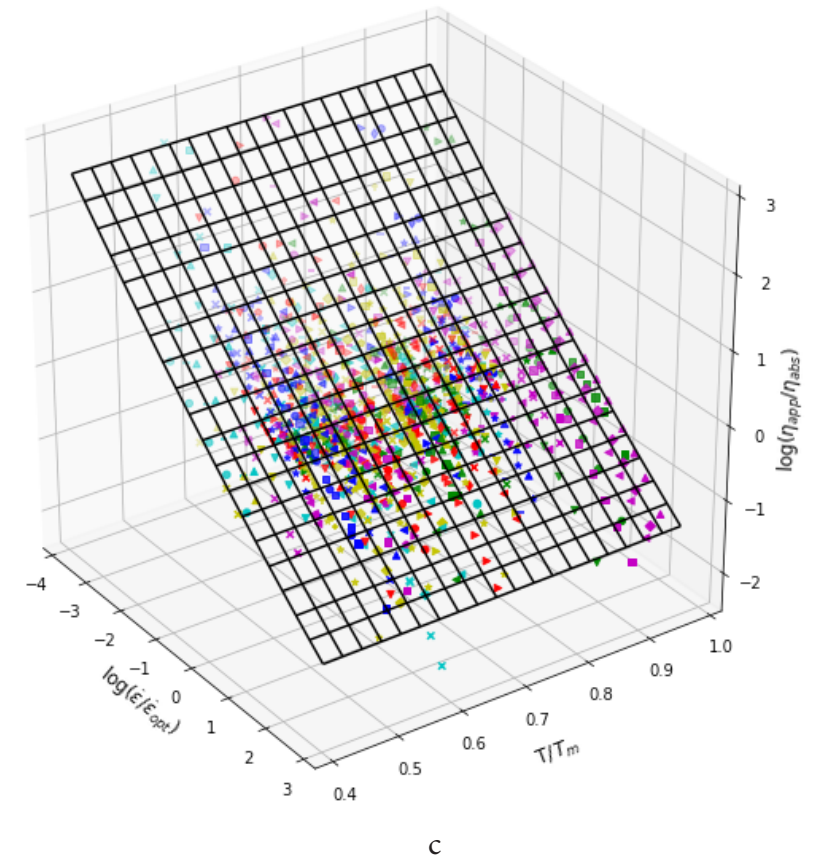

Fig. 4. (Color online) Universal surfaces $\log$ (normalized stress) vs. $\log$ (normalized strain rate) vs. $T_{\text {hom }}$ (a), normalized $m$ vs. $\log$ (normalized strain rate) vs. $T_{\text {hom }}$ (b), and $\log$ (normalized viscosity) vs. $\log$ (normalized strain rate) vs. $T_{\text {hom }}$ (c).

2. Eqs. (8)-(10) describe superplastic deformation in all classes of materials accurately. That is, in normalized space the superplastic response of materials of all classes, investigated employing widely varying experimental conditions, can be represented by these equations. Eqs. (5) - (7), on the other hand, make it clear that the fit is the best in the optimal region of isotropic, steady state superplastic flow. These observations also suggest that the underlying rate controlling mechanism in the optimal region of flow in all classes of materials is the same.

The above conclusions are arrived at by analyzing data pertaining to 175 material states, which include metals and alloys, ceramics, intermetallics, composites, nanostructured materials, bulk metallic glasses, geological materials and ice/ice-mixture. Therefore, confidence can be placed on these conclusions.

A survey of literature reveals that most workers suggest different rate controlling mechanisms for the optimal superplastic flow region in different materials, which is not consistent with the present findings based on the phenomenological description of the deformation process. However, there is an exception. In a series of publications, a physics-based model for grain boundary sliding (GBS) that develops to a mesoscopic scale (defined to be of the order of a grain diameter or more) has been proposed and it has been suggested that this process controls the rate of steady state isotropic optimal superplastic deformation in 
different classes of materials. This model has been verified and validated by carefully performed experiments and an analysis of the experimental data pertaining to different classes of superplastic materials. A detailed description of that model and its verification and validation can be found elsewhere [13-21,40-41]. In a recent paper [20], by analyzing the experimental data pertaining to different classes of superplastic materials (of 40 different chemical compositions and different constituent phases), it has been possible to propose a methodology for predicting the steady state, isotropic, optimal superplasticity of even so far untested materials with the help of four universal constants, whose values are given in the paper under reference [20]. This procedure requires no new experiments for describing steady state, isotropic, optimal superplastic flow in any, including untested, materials to an order of magnitude accuracy. The present work suggests that this approach has an edge over the other models proposed to date.

As Eqs. (4)-(6), (8)-(10) represent superplastic materials of all classes, optimal alloy design becomes possible. This possibility is briefly explained here with an example. Suppose one decides to develop a superplastic material with, say, titanium as the major constituent. From Eq. (4) one can obtain the likely real activation energy, $Q$, the material should have. This value is then compared with the real activation energy of pure titanium. As pointed out earlier, in this approach $Q$ is directly related to the shear modulus. Suitable alloy additions to Ti are known from the literature, e.g. Al, V etc. The shear moduli of different elements are listed by Frost and Ashby [42]. Using the rule of mixtures and past empirical knowledge available in literature, the percentages of the other elements to be added can be decided. Evidently, such an alloy has to be tested at conditions where $m=m_{\max }$. In Eq. (9), put $m=m_{\max }$. Decide the homologous temperature at which one wants to superplastically form this alloy. Then, solving Eq. (9) the strain rate at which the alloy should be deformed for the best results can be known.

It should be noted, however, that the average values for numerous alloys have been used to arrive at the above equations. Therefore, a few fine tuning experiments would be necessary to freeze the deformation conditions. But, such tests will be far less in number than would be the case with a trial and error approach. Focused research in this direction is likely to be very rewarding.

The experimental data analyzed in this paper correspond to a single starting microstructure in case of every material studied. It is highly desirable that the effect of grain size variation on superplastic deformation (by changing the starting grain size of every alloy) also is studied in great depth similar to the effects of strain rate, stress and temperature which have already been focused on. When such sets of experimental data are available, one will have to include one more normalized parameter in the analysis, viz., normalized grain size, i. e. the actual grain size divided by a rather large grain size at which superplastic effects would be absent/negligible.

From a practical point of view, it is desirable to extend the theoretical treatment (in the form of simulations) using Fig. 1 of [14] as the Representative Volume Element (RVE), employ the Phase Field Method coupled to Finite Element
Method, for example, and analyze the bulk and sheet metal deformation of superplastic materials. Efforts in this regard have just commenced.

\section{Conclusions}

The "universal nature" of steady state isotropic, optimal superplastic deformation, i.e., the presence of materialindependent 2D and 3D plots for the measurable parameters of superplastic deformation in materials of all classes in properly normalized spaces, is demonstrated with a high degree of accuracy by presenting these plots in dimensionless forms, i.e. normalized $\log$ (stress)-normalized $\log$ (strain rate)-homologous temperature; normalized strain rate sensitivity index - normalized $\log$ (strain rate) - homologous temperature; normalized $\log$ (viscosity)-normalized $\log$ (strain rate)-homologous temperature and melting temperature compensated activation energy for the rate controlling process in optimal superplastic deformation range vs. superplastic materials of different classes. This insight should facilitate a more efficient design and use of superplastic materials. That the ratio $\left(Q / R T_{\mathrm{m}}\right)$ is nearly constant for superplastic materials of different classes is yet another argument in favor of a common origin of the phenomenon of Optimal Structural Superplasticity. The very close proximity of the curves for different materials becomes less close as one moves away from the optimal range of superplastic flow. At the lower region of strain rate, the decrease in the $m$ value below $\approx 0.3$ and the loss of superplasticity is attributed in some approaches to the presence of a threshold stress, which could vary significantly from one material to the next. This makes the superposition of curves for the different materials less good in the region $0<m<0.3$. At the higher extremes of strain rates $\left(\dot{\varepsilon}>\dot{\varepsilon}_{\text {opt }}\right)$, the loss of Superplasticity is traced in many models to deformation processes like dislocation glide, climb etc., which are strongly dependent on the crystal structure, alloy composition and the phases present. In this range also the fit is less good than what is seen in the optimal range. Therefore, in both the non-optimal superplastic flow regions present at either end of the optimal range, the superposition of the curves pertaining to different materials is less good. Therefore, it is concluded based on the phenomenology of superplastic flow that the occurrence of this phenomenon in the optimal region of deformation in materials of all classes has a common origin. Among the several models proposed to date in order to explain steady state optimal, isotropic Structural Superplasticity, one model, in which grain boundary sliding develops to a mesoscopic scale and controls the rate of deformation, meets this criterion imposed by the phenomenology of the flow process that a single mechanism should be able to describe this nearubiquitous phenomenon.

Supplementary material. The online version of this paper contains supplementary material available free of charge at the journal's Web site (lettersonmaterials.com).

Acknowledgments. Prof. $R$ A Vasin, till recently of Moscow State University, was also in the 1990s the Head of the Mechanics 
Laboratory at the Institute of Metals Superplasticity Problems of the Russian Academy of Sciences (IMSP RAS), Ufa, Russia. The founder Director of IMSP, Prof. O A Kaibyshev introduced Prof. Vasin to one of the authors, K A Padmanabhan (KAP). This led to a strong collaboration between Prof. Vasin and KAP and they wrote the book "Superplastic Flow: Phenomenology and Mechanics", with F U Enikeev also as a coauthor (Springer Verlag, Berlin-New York, 2001). While writing this book, the research problem discussed in the present paper was discussed by KAP and Prof. Vasin. But they moved on to other topics in later years. When KAP solved this problem recently collaborating with his students, he decided to invite Prof. Vasin to be a coauthor. But, to his great sadness KAP learnt that Prof. Vasin is no more. This paper is humbly dedicated by the authors to the immortal memory of the true scholar and academic, Prof. R A Vasin.

Harisankar thanks Dr. B P Gautham and Dr. G Tennyson, both of TCS, for their encouragement.

This research did not receive any specific grant from funding agencies in the public, commercial, or not-for-profit sectors.

Conflict of Interest. The authors declare that they have no conflict of interest.

Data Availability. The raw/processed data required to produce these findings can be shared with anyone on reasonable request.

\section{References}

1. K.A. Padmanabhan, S.B. Prabu, R.R. Mulyukov, A. Nazarov, R. M. Imayev, S. G. Chowdhury. Superplastic flow: common basis for a ubiquitous phenomenon. Springer-Verlag, Berlin Heidelberg, New York (2018). Crossref

2. K.A. Padmanabhan, G. J. Davies. Superplasticity: mechanical and structural aspects, environmental effects, fundamentals and applications. Springer-Verlag, Berlin Heidelberg, New York (1980). Crossref

3. T. G. Nieh, J. Wadsworth, O. D. Sherby. Superplasticity in metals and ceramics. Cambridge University Press, UK (1997). Crossref

4. O. A. Kaibyshev. Superplasticity of alloys, intermetallides and ceramics. Springer-Verlag, Berlin Heidelberg, NewYork (1992). $\underline{\text { Crossref }}$

5. M. Jime’nez-Melendo, A. Domi'nguez-Rodri'guez, M. Holgado-Salado. Int. J. Plast. 17, 341 (2001). Crossref

6. J. N. Wang, Y. Wang. Int. J. Plast. 22, 1530 (2006). Crossref

7. M. Mabuchi, K. Higashi. Int. J. Plast. 17, 399 (2001). Crossref

8. R. Boissière, J. J. Blandin, L. Salvo. J. Eng. Mater. Technol. 130 (2), 1 (2008). ㄷossref

9. K. M. Liew, H. Tan, M. J. Tan. J. Eng. Mater. Technol. 125 (3), 256 (2003). Crossref

10. H. Masuda, E. Sato. Acta Mater. 197, 235 (2000). Crossref

11. K.A. Padmanabhan. Scr. Metall. 7, 137 (1973). Crossref

12. K. A. Padmanabhan. Mater. Sci. Eng. 29, 1 (1977). $\underline{\text { Crossref }}$
13. K. A. Padmanabhan, J. Schlipf. Mater. Sci. Technol. 12, 391 (1996). Crossref

14. K. A. Padmanabhan, H. Gleiter. Mater. Sci. Eng. A. 381, 28 (2004). Crossref

15. K. A. Padmanabhan, G. P. Dinda, H. Hahn, H. Gleiter. Mater. Sci. Eng. A. 452, 462 (2007). Crossref

16. K. A. Padmanabhan. J. Mater. Sci. 44, 2226 (2009). Crossref

17. K. A. Padmanabhan, M. I. R. Basariya. Int. J. Mater. Res. 100, 1543 (2009). Crossref

18. K. A. Padmanabhan, M. I. R. Basariya. Mater. Sci. Eng. A. 527, 225 (2009). Crossref

19. K. A. Padmanabhan, H. Gleiter. Curr. Opin. Solid State Mater. Sci. 16 (5), 243 (2012). Crossref

20. K. A. Padmanabhan, M. I. R. Basariya. Mater. Sci. Eng. A. 744, 704 (2019). Crossref

21. T. A. Venkatesh, S.S. Bhattacharya, K.A. Padmanabhan, J. Schlipf. Mater. Sci. Technol. 12, 635 (1996). Crossref

22. M.S. Mohebbi, A. Akbarzadeh. Int. J. Plast. 90, 167 (2017). Crossref

23. N. C. Admal, G. Po, J. Marian. Int. J. Plast. 106, 1 (2018). Crossref

24. T. Cheng, Y. Wen, J. A. Hawk. Int. J. Plast. 114, 106 (2019). Crossref

25. I. A. Ovid'ko, A. G. Sheinerman. Int. J. Plast. 96, 227 (2017). Crossref

26. D. M. Owen, A.H. Chokshi. Int. J. Plast. 17, 353 (2001). Crossref

27. M. Lagos, H. Duque. Int. J. Plast. 17 (3), 369 (2001). Crossref

28. M.F. Horstemeyer, D. J. Bammann. Int. J. Plast. 25 (9), 1310 (2010). Crossref

29. F. P. E. Dunne. Int. J. Plast. 14 (4-5), 413 (1998). Crossref

30. M. A. Khaleel, H. M. Zbib, E. A. Nyberg. Int. J. Plast. 17, 277 (2001). Crossref

31. K.A. Padmanabhan, R.A. Vasin, F.U. Enikeev. Superplastic Flow: Phenomenology and Mechanics. Springer Verlag, New York (2001). Crossref

32. R. A. Vasin, V. K. Berdin, R. M. Kashaev. Strength Mater. 33, 509 (2001). Crossref

33. A. A. Sirenko, M. A. Murzinova, F. U. Enikeev. J. Mater. Sci. Lett. 14, 773 (1995). Crossref

34. F. U. Enikeev, K.A. Padmanabhan, S.S. Bhattacharya. Mater. Sci. Technol. 15, 673 (1999). $\underline{\text { Crossref }}$

35. Y. Kawamura, T. Nakamura, A. Inoue, T. Masumoto. Mater. Trans. JIM. 40, 794 (1999). Crossref

36. F. K. Abu-Farha, M. K. Khraisheh. J. Eng. Mater. Technol. 127 (1), 159 (2005). Crossref

37. K.A. Padmanabhan, J. Leuthold, G. Wilde, S. S. Bhattacharya. Mech. Mater. 91, 177 (2015). Crossref

38. I. C. Trelea. Inf. Proc. Lett. 85, 317 (2003). Crossref

39. Pyswarm. https://pythonhosted.org/pyswarm/ Accessed: November (2019).

40. U. Betz, K. A. Padmanabhan, H. Hahn. J. Mater. Sci. 36, 5811 (2001). Crossref

41. H. Hahn, K. A. Padmanabhan. Philos. Mag. B. 76, 559 (1997). Crossref

42. H. J. Frost, M.F. Ashby. Deformation mechanism maps. Pergamon Press, Oxford (1982). 